\title{
Effect of Antiretroviral Therapy (ART) on HIV-1 \& 2 (Subtype C) infection and its relationships to cognitive function and quality of life
}

\author{
Gopukumar Kumarpillai ${ }^{1 *}$, Shobini L Rao ${ }^{1,2}$, Prabha S Chandra ${ }^{1,2}$, P Satishchandra ${ }^{1,2}$, Mahendra Kumar ${ }^{1,2,3}$ \\ From $16^{\text {th }}$ International Symposium on HIV and Emerging Infectious Diseases \\ Marseille, France. 24-26 March 2010
}

\section{Background}

To study the effect of Antiretroviral Therapy on neuropsychological functioning and quality of life of Seropositive HIV-1 Clade C infected subjects from South India.

\section{Methods}

A sample of 128 HIV-1 positive adults was recruited during 2003-2007. Of the 128 subjects, 8 were HIV-2 positive, 6 deaths and 2 dropouts during the 4 follow-up and were excluded from analyses. The present study conducted after the 4th follow-up and the final sample consisted of 112 seropositive HIV-1 Clade C infected subjects, 83 of them are not on ART (mean age $30 \pm 4.35$ ) and 29 of them are on ART (29.7 \pm 5.75 years). Neuropsychological tests were administered in the domains of attention, fluency, motor speed, verbal and visual working memory, response inhibition, planning and verbal and visual learning \& memory. WHOQOL-HIV BREF was also used to analyze the following domains of quality of life viz., physical health, psychological, level of independence, social relations, environment and spiritual beliefs. Mean and SD were calculated. Analysis of Variance (ANOVA) and Correlation were used to analyse the data. All statistical analysis were done using SPSS version 15.

\section{Results}

Analysis between ART and Non-ART groups differ on design fluency score $(\mathrm{p}<0.05)$ and figural scanning $(\mathrm{p}<0.05)$. Similarly, QOL domain significantly differs only on social relations $(\mathrm{p}<0.01)$. Analysis between neuropsychological measures and quality of life (QOL) scores revealed significant correlation between QOL Total and motor speed ( $\mathrm{p}<0.01)$ and verbal fluency $(\mathrm{p}<0.01)$. Social relations significantly correlate on verbal working memory $(\mathrm{p}<0.05)$, auditory verbal learning $(\mathrm{p}<0.05)$, verbal memory $(\mathrm{p}<0.05)$, verbal fluency $(\mathrm{p}<0.05)$ and color trails $(\mathrm{p}<0.05)$. Spiritual beliefs significantly correlate only of color trails $(\mathrm{p}<0.05)$.

\section{Discussion}

Neuropsychological functioning and quality of life and with ART treatment revealed that ART success was significantly related to motor speed and fluency. Better neuropsychological performance may lead to more available social contacts and increase spiritual beliefs. In addition, none of the subjects developed any functional impairment.

\section{Author details}

'University of Calgary, Calgary, Canada. ${ }^{2}$ NIMHANS, Bangalore, India. ${ }^{3}$ Miami School of Medicine, Florida, USA.

Published: 11 May 2010

doi:10.1186/1742-4690-7-S1-P13

Cite this article as: Kumarpillai et al.: Effect of Antiretroviral Therapy

(ART) on HIV-1 \& 2 (Subtype C) infection and its relationships to

cognitive function and quality of life. Retrovirology 2010 7(Suppl 1):P13.

* Correspondence: drgopukumar@gmail.com

'University of Calgary, Calgary, Canada 